\title{
On design criteria for a disconnectable FPSO mooring system associated with expected life-cycle cost
}

José Manuel Cabrera-Miranda a,b, Patrícia Mika Sakugawa ${ }^{\mathrm{c}}$, Rafael

Corona-Tapia $^{\mathrm{d}}$ and Jeom Kee Paik ${ }^{\mathrm{a}, \mathrm{b}, \mathrm{e}, *}$

${ }^{a}$ Department of Naval Architecture and Ocean Engineering, Pusan National University, Busan 46241, Republic of Korea

${ }^{b}$ The Korea Ship and Offshore Research Institute (The Lloyd's Register Foundation Research Centre of Excellence), Pusan National University, Busan 46241, Republic of Korea

${ }^{c}$ Department of Mechanical Engineering \& Post-Graduate Program in Science and Petroleum Engineering, University of Campinas, Campinas, São Paulo, Brazil

dInfraestructura y Evaluación, Coordinación de Diseño, Gerencia de Administración de Asignaciones en Aguas Profundas, Bloques Norte, Pemex Exploración y Producción, Tampico 89000, Tamaulipas, México

${ }^{e}$ Department of Mechanical Engineering, University College London, London WC1E $7 J E, U K$

*Corresponding author. Tel.: +8251510 2429; fax: +82 51518 7687. E-mail address: jeompaik@pusan.ac.kr

ORCID: José Manuel Cabrera-Miranda http://orcid.org/0000-0001-9991-0685;

Patrícia Mika Sakugawa http://orcid.org/0000-0001-9677-5879. 


\begin{abstract}
Some floating production, storage, and offloading units (FPSOs) possess disconnectable systems to avoid harsh environments. According to a literature survey, the practice is based on perceptions and experiences of operators to judge disconnection; however, this paper offers a rational approach. A life-cycle cost model is proposed to optimize (1) the disconnection criteria and (2) the design of mooring lines under reliability format. Relevant ultimate limit states are considered in association with hull, moorings and green water failure. Effects of future failure costs is considered (downtime, environmental damage, reputation, etc.). Disconnection criteria are then formulated in terms of significant wave height and wind speed limits. Because a permanent mooring system may exhibit excessive resistance, it is possible to reduce the lines' thickness until the cost is optimized for non-permanent service. Results for an example in the Gulf of Mexico show that important savings can be achieved by implementing the proposed optimizations.
\end{abstract}

Keywords: disconnection criteria; FPSO; life-cycle cost; mooring system; target reliability index; ultimate limit state.

\title{
1. Introduction
}

Floating production, storage, and offloading (FPSO) systems are a proven technology for the development of deep offshore oil fields. Some FPSOs with single-point mooring systems (SPMs) can be disconnected to avoid extreme environmental loads, sail toward sheltered areas, and restart operations when the weather becomes benign.

Disconnectable systems have several advantages such as lowering design loads, reducing risk to asset damage, making the production of lost infrastructure autonomous 
and eliminating the need of helicopter evacuations (Daniel et al. 2013). However, complex mechanisms are required for disconnection and reconnection (Shimamura 2002).

Disconnectable SPMs for FPSOs can be classified into (Li et al. 2014) those with fast [see for example Mastrangelo et al. (2007), Daniel et al. (2013) and Leon (2016)] and regular disconnection functions [see for example Aanesland et al. (2007)]. The former necessitate self-propulsion to avoid cyclonic storms and the latter cannot really evade storms but could be upgraded.

In the codes, disconnectable floating production systems are required to withstand the maximum design conditions when the threshold environment for disconnection is reached (API 2001) and to possess self-propulsion (ABS 2014; LR 2016); nevertheless, it is outside the scope of these codes to set any disconnection criteria.

Life-cycle cost analysis (LCCA) consists of adding the initial costs such as engineering, purchase, fabrication and installation costs, to future costs such as failure, operation, maintenance, and decommissioning. Stahl (1986) proposed its application for fixed offshore structures and Bea (1994) for crude-oil carriers. In 1994 and 1997, the International Ship and Offshore Structures Congress (ISSC) adopted the LCCA as tool to evaluate the risks of ship structures (Béghin 2010).

LCCA has been used to optimize reliability indices for the design of fixed offshore structures (Stahl et al. 2000; Kübler \& Faber 2004; Campos et al. 2013; Lee et al. 2016), 
to establish reliability-based inspection plans (Moan 2011) and to define a lower deck elevation for fixed offshore platforms (Campos et al. 2015). Bayesian probabilistic network-based consequence models have been used to derive target reliability indices for the design of FPSOs (Faber et al. 2012; Heredia-Zavoni et al. 2012). A multidisciplinary optimization of vessel costs with an enhanced multiple-objective collaborative optimizer was developed for the design of naval ships (Temple \& Collette 2017).

Marine operations have also been optimized, such as those of the transfer arm for liquefied natural gas in combination with a fuzzy logic algorithm (Nwaoha 2014), the ship oil-drain intervals with oil-analysis program data interpretation (Langfitt \& Haselbach 2016), vessel chartering strategies for offshore wind farms (Dalgic, Lazakis, Dinwoodie, et al. 2015; Dalgic, Lazakis, Turan, et al. 2015) and overall wind farms costs (Lagaros et al. 2015).

The objective of this paper is to derive the target reliability index for the ultimate limit state (ULS) design of lines in disconnectable mooring systems with fast disconnection function. A target reliability index and associated limit conditions are obtained by minimizing the life-cycle costs.

The current condition for FPSO disconnection is the occurrence of cyclonic storms. Although extensive research has been conducted on the life-cycle cost-based optimization of offshore structures, to our knowledge, no attempt has been made to optimize the disconnection criteria. In this regard, this paper offers a novel approach to 
determine the maximum environmental conditions that the mooring system shall withstand as well as a criterion for reliability-based design in ULS. Even though it is out of the scope for this study, the proposed model can be easily extended for other limit states and for permanent mooring systems.

\section{Life-cycle cost model}

The expected present value of the total life-cycle cost $C_{T}$ can be expressed as

$$
E\left[C_{T}\right]=E\left[C_{I}\right]+E\left[C_{F}\right]
$$

where $E[\cdot]$ denotes expected value, $C_{I}$ is the initial costs and $C_{F}$ the future costs.

$E\left[C_{I}\right] \approx C_{I}$ is a reasonable approximation. Neglecting the failure-independent operational expenditure, Eq. (1) is rewritten as

$$
E\left[C_{T}\right]=C_{I}+\sum c_{i}\left(P_{f i}\right)
$$

where $c_{i}$ is the expected future cost for the $i$-th limit state as a function of its annual probability of failure $P_{f i}$.

\subsection{Components of Future costs}

A holistic model proposed by De Leon and Ang (2008) is employed and extended by including reputational losses, which have shown to be relevant to firms (Eckert \& Gatzert 2017). Each future cost (failure cost or risk expenditure) can then be written as

$$
c_{i}\left(P_{f i}\right)=E\left[C_{R i}\right]+E\left[C_{M i}\right]+E\left[C_{W i}\right]+E\left[C_{L i}\right]+E\left[C_{E D i}\right]+E\left[C_{D P i}\right]+E\left[C_{R D i}\right]
$$


where the cost components comprise replacement $C_{R i}$, mobilization $C_{M i}$, wounds $C_{W i}$, life loss $C_{L i}$, environmental damage $C_{E D i}$, deferred production $C_{D P i}$ and reputational damage $C_{R D i}$.

Six limit states are considered in the model and reported in Table 1. A rigorous discussion of FPSO limit states is available in an HSE report (Noble Denton Europe Ltd 2001).

Table 1. Limit states and assumptions for calculating failure costs.

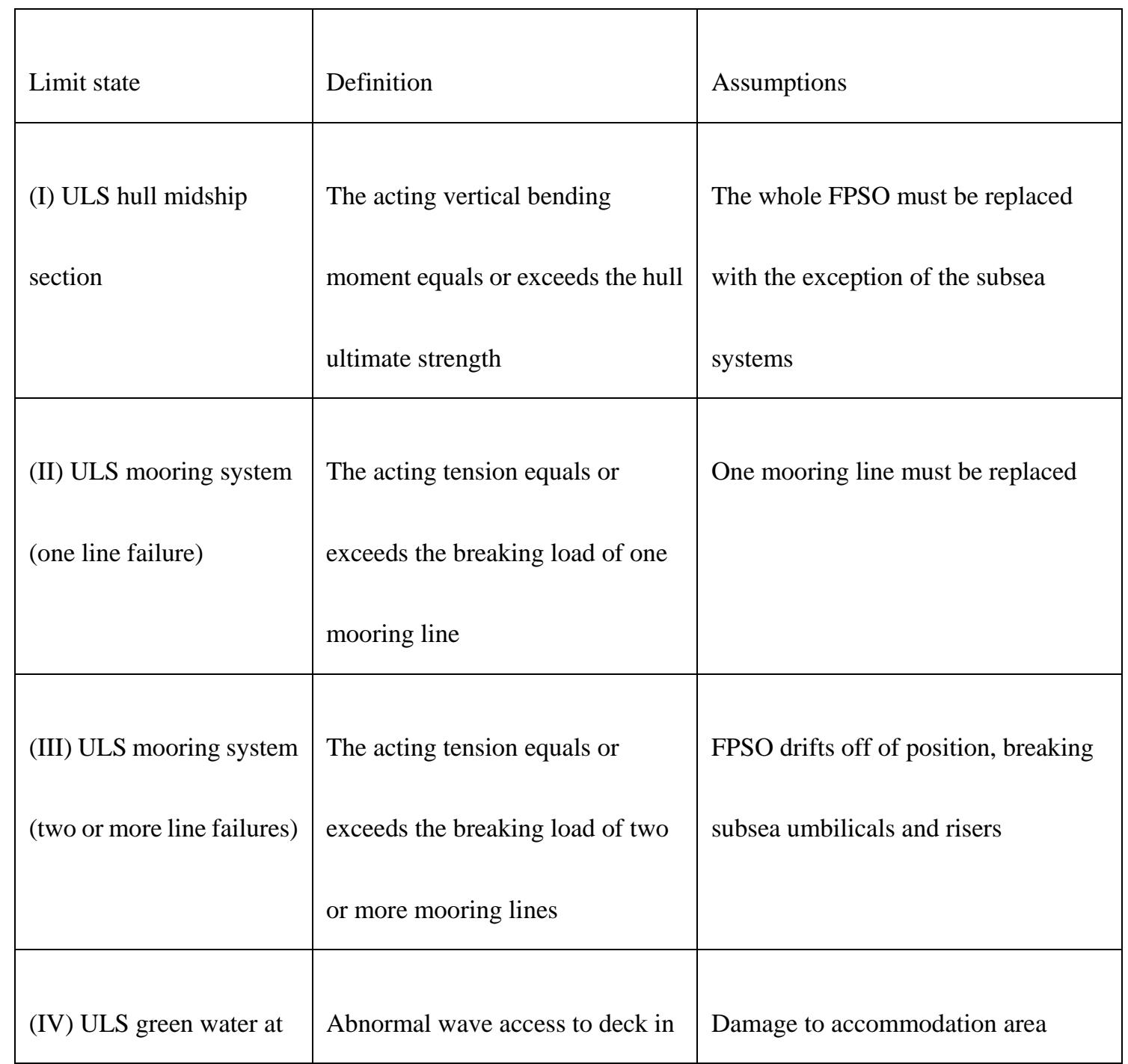




\begin{tabular}{|l|l|l|}
\hline accommodation area & accommodation area & \\
\hline (V) ULS green water not & Abnormal wave access to deck in & Damage to tanks and processing \\
at accommodation area & process or utility areas & equipment \\
\hline (VI) Disconnection & FPSO is disconnected to avoid & FPSO is disconnected, mobilized to \\
& anticipated extreme loads & port under self-propulsion, \\
& & re-mobilized to site, and reinstalled \\
\hline
\end{tabular}

\subsection{Expected future costs}

By following Stahl (1986), a general future cost $C_{G i}$ at time $t$ can be estimated by means of the annual inflation rate $r$ in the form of

$$
\left.C_{G i}\right|_{t=t}=\bar{C}_{G i} \exp (r t)
$$

where $\overline{C_{G i}}$ is the equivalent cost of failure evaluated at $t=0$.

By bringing the future costs to $t=0$, Eq. (4) becomes

$$
\left.C_{G i}\right|_{t=0}=\bar{C}_{G i} \exp (r t) \exp (-j t)
$$

where $j$ is the annual discount rate.

The expected future cost is given by

$$
\left.E\left[C_{G i}\right]=\int_{0}^{T} \bar{C}_{G i} P_{f} x_{i} \mathbf{p}^{-}\right) k t
$$


where $k=j-r$ is the net annual discount rate and $T$ is the project life.

Solving the integral in Eq. (6) for the costs components in Eq. (3), the following is obtained:

$$
\begin{gathered}
E\left[C_{R i}\right]=\bar{C}_{R i} P_{f} \mathrm{PVF} \\
E\left[C_{M i}\right]=\bar{C}_{M i} P_{f} \mathrm{PVF} \\
E\left[C_{W i}\right]=\bar{C}_{W i} P_{f} \mathrm{PVF} \\
E\left[C_{L i}\right]=\bar{C}_{L i} P_{f} \mathrm{PVF} \\
E\left[C_{E D i}\right]=\bar{C}_{E D i} P_{f} \mathrm{PVF} \\
E\left[C_{R D i}\right]=\bar{C}_{R D i} P_{f} \mathrm{PVF}
\end{gathered}
$$

where

$$
\mathrm{PVF}=[1-\exp (-k T)] / k
$$

is the present value function.

Furthermore, if the FPSO fails at $t$, the deferred production cost under the assumption of replacement after failure is given by

$$
C_{D P i}(t)=\int_{t}^{T} R(\tau) \exp [-k(\tau-t)] d \tau-\int_{t+\Delta T_{i}}^{T+\Delta T_{i}} R(\tau) \exp [-k(\tau-t)] d \tau
$$

where $R(t)$ is the revenue stream from the product exploitation at $t$ and $\Delta T_{i}$ is the period of deferred production. Substitution of Eq. (14) into (6) gives 


$$
E\left[C_{D P i}\right]=P_{f i} \int_{0}^{T} C_{D P i}(t) \exp (-k t) d t
$$

\subsection{Probability of failure}

Using the underscore to indicate random variables, the event that the FPSO is connected is defined by the space $\underline{H_{S}}<H_{L} \cap \underline{U}<U_{L}$, where $\underline{H_{S}}$ is the significant wave height, $H_{L}$ is the significant wave height limit for disconnection, $\underline{U}$ is the wind speed, and $U_{L}$ is the wind speed limit for disconnection. Noting that the FPSO can only fail in the said space, the probability of failure is written as

$$
P_{f i}=\mathrm{P}\left\{\underline{S_{i}} \geq \underline{R_{i}} \cap\left(\underline{H_{S}}<H_{L} \cap \underline{U}>U_{L}\right)\right\}
$$

where $\mathrm{P}\{\cdot\}$ denotes the probability, $\underline{S_{i}}$ is the solicitation (load or demand), and $\underline{R_{i}}$ is the resistance (strength or capacity) for the $i$-th limit state.

Regarding limit state (I), two failure modes are possible: hogging and sagging bending moment failures and therefore Eq. (16) takes the form of

$$
P_{f 1}=\mathrm{P}\left\{\left(\underline{\mathcal{R}_{1, h o g}}-\underline{S_{1, s w}}-\underline{S_{1, w v-h o g}} \leq 0\right) \cup\left(\underline{R_{1, s a g}}-\underline{S_{1, s w}}-\underline{S_{1, w v-s a g}} \geq 0\right) \cap\left(\underline{H_{S}}<H_{L} \cap \underline{U}<U_{L}\right)\right\}
$$

where $\underline{\mathcal{R}_{1, h o g}}$ is the hull ultimate strength in the hogging condition, $\underline{S_{1, s w}}$ is the still-water bending moment, $\underline{S_{1, w v-h o g}}$ is the hogging vertical wave-induced bending moment, $\underline{R}_{1, s a g}$ is the hull ultimate strength in the sagging condition, and ${\underline{S_{1, w v-s a g}}}$ is the sagging vertical wave-induced bending moment.

For the mooring system, each line is a serial system composed of various sections. The probability that one line gets broken is conveniently expressed as 


$$
P_{f 2}=\mathrm{P}\left\{(\underline{N}=1) \cap\left(\underline{H_{S}}<H_{L} \cap \underline{U}<U_{L}\right)\right\}
$$

and the probability that two or more lines get broken is

$$
P_{f 3}=\mathrm{P}\left\{(\underline{N} \geq 2) \cap\left(\underline{H_{S}}<H_{L} \cap \underline{U}<U_{L}\right)\right\}
$$

where $\underline{N}$ states for the number of broken lines.

The probability of green water at the accommodation area can be calculated as

$$
P_{f 4}=\mathrm{P}\left\{\left(\underline{S_{4}} \leq 0\right) \cap\left(\underline{H_{S}}<H_{L} \cap \underline{U}<U_{L}\right)\right\}
$$

and the probability of green water at other areas is expressed as

$$
P_{f 5}=\mathrm{P}\left\{\left(\underline{S_{5}} \leq 0\right) \cap\left(\underline{H_{s}}<H_{L} \cap \underline{U}<U_{L}\right)\right\}
$$

where $\underline{S_{4}}$ and $\underline{S_{5}}$ represent the vertical relative motion of the deck with respect to the wave surface at the accommodation area and other areas, respectively.

The failure space for limit state (VI) is the complement of the connected FPSO event space, i.e.

$$
P_{f 6}=\mathrm{P}\left\{\underline{H_{S}} \geq H_{L} \cup \underline{U} \geq U_{L}\right\} .
$$

\subsection{Optimization of disconnectable moorings}

The optimum expected life-cycle cost can be stated as

$$
C_{\text {Topt }}=C_{I}+\min \left\{\sum P_{f i}\left(H_{L}, U_{L}\right)\right\}, \forall\left(H_{L}, U_{L}\right) \in[0, \infty) \times[0, \infty)
$$


which is associated with an optimum $H_{L}$ and an optimum $U_{L}$.

Furthermore, the optimization of $C_{\text {Topt }}$ is possible by solving

$$
C_{\text {Topt-moor }}=\min \left[C_{\text {Topt }}(\gamma)\right], \forall \gamma \in[0, \infty)
$$

where $C_{\text {Topt-moor }}$ is the optimum expected life-cycle cost for an optimized mooring system and $\gamma\left(\mathcal{R}_{\text {moor }}\right)$ is a function that characterizes the mooring system resistance $\mathbb{R}_{\text {moor }}$. For this model, the functions of $\gamma$ are: $C_{I}(\gamma), \bar{C}_{R 2}(\gamma), \bar{C}_{M 2}(\gamma), \bar{C}_{R 3}(\gamma)$, $\bar{C}_{M 3}(\gamma), P_{f 2}(\gamma)$, and $P_{f 3}(\gamma)$. In Section 4.2, $\gamma\left(R_{\text {moor }}\right)$ is taken as the minimum breaking load (MBL).

Because limit states (II) and (III) exclude each other, the probability of failure of the mooring system $P_{\text {fmoor }}$ is simply calculated as

$$
P_{\text {fmoor }}=P_{f 2}+P_{f 3}
$$

and the mooring system reliability index $\beta_{\text {moor }}$ is defined as

$$
\beta_{\text {moor }}=-\Phi^{-1}\left(P_{\text {fmoor }}\right)
$$

where $\Phi^{-1}(\cdot)$ is the inverse standard normal cumulative distribution function.

The target $\beta_{\text {moor }}$ is the one associated with $C_{\text {Topt-moor }}$ in Eq. (24) because this value minimizes the life-cycle cost of a disconnectable FPSO.

The proposed life-cycle cost model was implemented in a Matlab routine which algorithm is given in Fig. 1. 


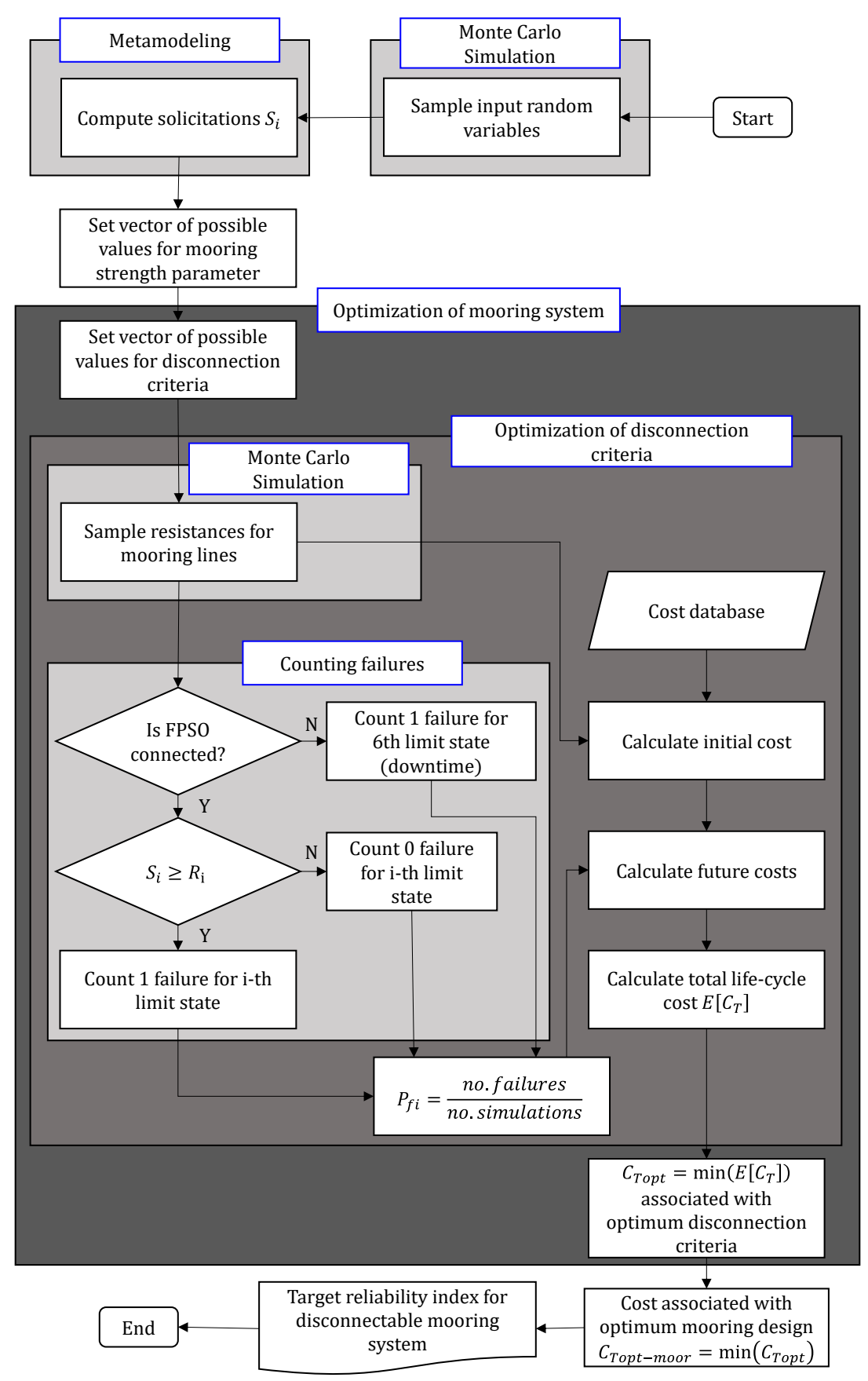

Figure. 1. Flow chart for the optimization of disconnectable FPSO mooring lines. 


\section{Applied example}

\subsection{FPSO characteristics}

Let a hypothetical tanker-based FPSO be considered for service in the Mexican Gulf of Mexico in a 3,100 $\mathrm{m}$ water depth over $15 \mathrm{yr}$ with dimensions presented in Table 2. Her mooring system is of the SPM buoy turret mooring type with fast disconnection function (self-propulsion included).

Table 2. FPSO main particulars.

\begin{tabular}{|r|r|}
\hline Particular & \multicolumn{2}{|c|}{ Dimension } \\
\hline Length between perpendiculars & $239 \mathrm{~m}$ \\
\hline Breadth & \\
\hline Depth & \\
\hline Dead weight & $21 \mathrm{~m}$ \\
\hline Total cargo capacity & $107,000 \mathrm{~m}^{3}(680,000 \mathrm{bbl})$ \\
\hline
\end{tabular}

The mooring system consists 12 taut legs organized in three clusters. Each line is composed of a $114.3 \mathrm{~mm} \times 150 \mathrm{~m}$ grade 4 chain bottom section; a $190.5 \mathrm{~mm} \times 3,704 \mathrm{~m}$ polyester section; and a $114.3 \mathrm{~mm} \times 150 \mathrm{~m}$ grade 4 chain top section in length. The system was designed according to industry-accepted guidelines (API 2005; DNV GL 2015). 


\subsection{Solicitation metamodels}

A metamodel approach was used to approximate the solicitations as functions of several input parameters. Background (Fang et al. 2006) and applications are documented elsewhere (Yang \& Zheng 2011; Garrè \& Rizzuto 2012; Cabrera-Miranda \& Paik 2017).

Latin hypercube sampling was applied to select 50 scenarios (see Table 3). The wave parameters were taken from DNV (2014), and wind and current distributions were derived from data in API (2007). The directions of the environment were approximated by means of directional functions, and the vessel's draft was an assumption.

Table 3. Probabilistic distribution of input variables for the solicitation metamodels.

\begin{tabular}{|r|r|l|}
\hline \multicolumn{1}{|c|}{ Variable } & Unit & Distribution \\
\hline Significant wave height & $\mathrm{m}$ & Weibull $(\alpha=1.81, \beta=1.47)$ \\
\hline Zero-crossing wave period & $\mathrm{s}$ & Lognormal distribution \\
& & $\left(\mu=0.7+0.95 H_{S}{ }^{0.158}\right.$, \\
Wave direction angle with respect & $\operatorname{rad}$ & \\
to peak direction & & Directional function $(s=5)$ \\
\hline
\end{tabular}




\begin{tabular}{|l|l|l|}
\hline 1-h average wind speed at $10 \mathrm{~m}$ & $\mathrm{~m} \cdot \mathrm{s}^{-1}$ & Log-normal $(\mu=0.61, \sigma$ \\
above sea level & & $=0.725)$ \\
\hline Wind direction angle respect to & $\mathrm{rad}$ & Directional function $(s=5)$ \\
peak direction & $\mathrm{m} \cdot \mathrm{s}^{-1}$ & Log-normal $(\mu=-1.1187, \sigma$ \\
\hline Current speed at surface & & $=0.432)$ \\
\hline Current direction angle respect to & $\mathrm{rad}$ & Directional function $(s=5)$ \\
\hline peak direction & $\mathrm{m}$ & Uniform $(6.38,15.85)$ \\
\hline Draft & & \\
\hline
\end{tabular}

For each scenario, station-keeping analyses were conducted with ANSYS Aqwa in the time-domain. Irregular waves were defined by the Pierson-Moskowitz spectrum, the wind by the ISO spectrum, and the current by a slab profile. From the responses time series (see Fig. 2), maximum responses were obtained or minimum where relevant (sagging moment and vertical relative motion). Throughout this paper, results for mooring line tensions are shown for the most loaded line. 

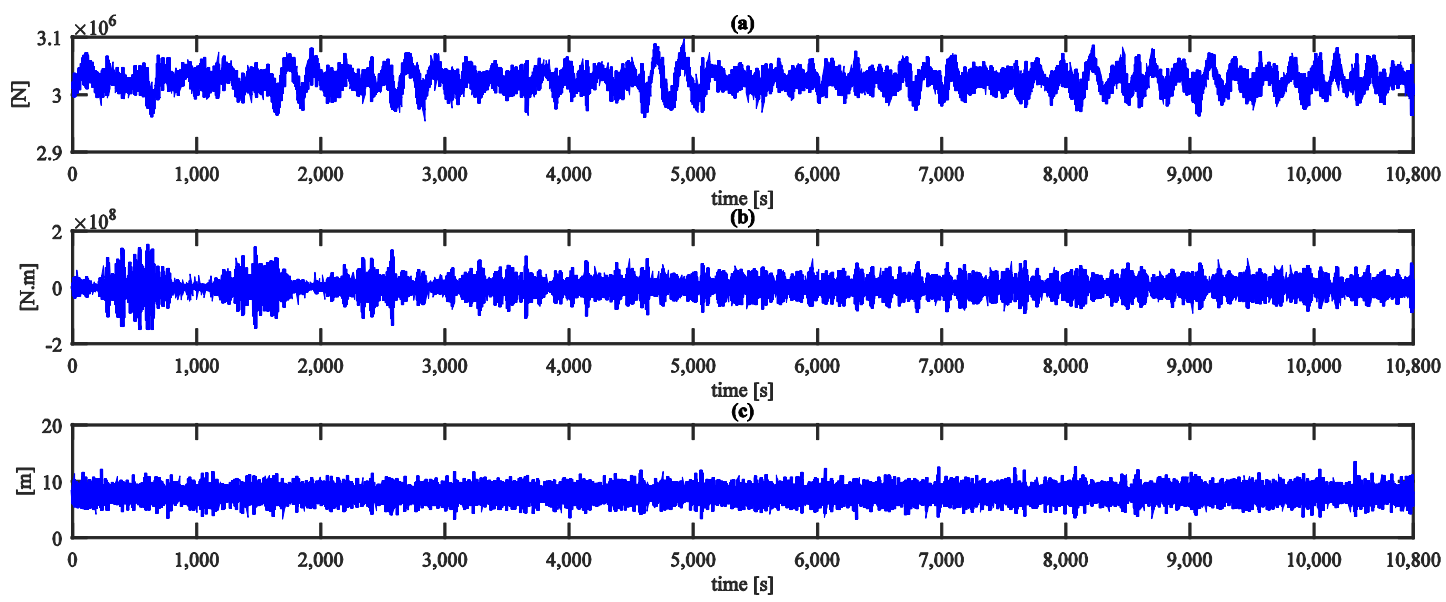

Figure. 2. Time-domain series of FPSO responses of a typical scenario for (a) mooring line tension at the top chain section, (b) vertical wave-induced bending moment, and (c) deck vertical motion relative to the wave surface at bow.

The responses are then used to construct Kriging metamodels for the solicitations by means of the ooDACE Matlab toolbox (Couckuyt et al. 2010; Couckuyt et al. 2012; Ulaganathan et al. 2015). Overall, 42 metamodels were computed and some examples are shown in Fig. 3. Initially, metamodels were inaccurate for extreme loads, and therefore 10 additional scenarios were uniformly sampled between the maximum values of the LHS and the $100 \mathrm{yr}$ return period conditions to improve predictions. Furthermore, wind speed and its direction, and current speed and its direction were excluded from the models for bending moments to reduce the mean error. 


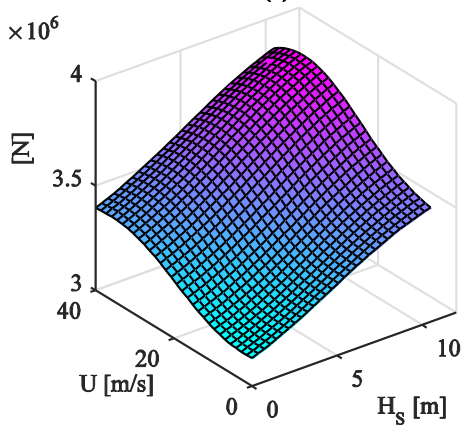

(b)

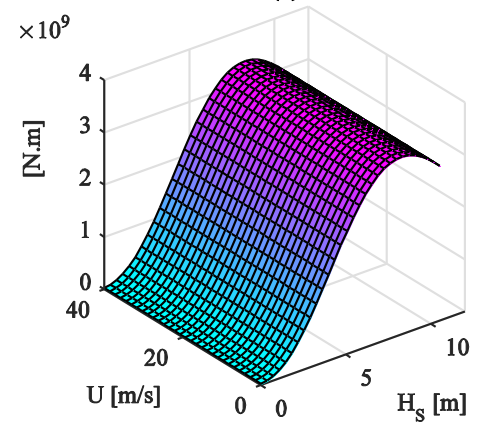

(c)

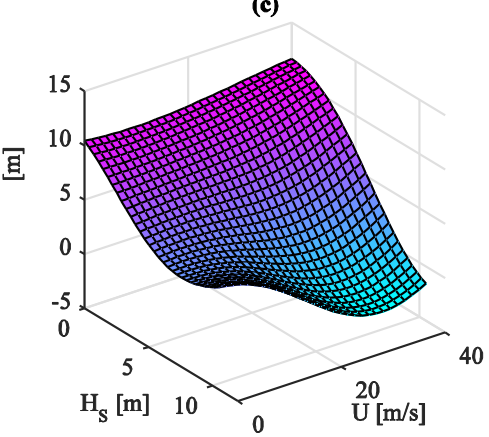

Figure 3. Predicted solicitations by Kriging metamodels (variables not shown are set to mean value) for (a) mooring line tension at the top chain section, (b) hogging vertical wave-induced bending moment, and (c) deck vertical motion relative to the wave surface at bow.

\subsection{Reliability analysis}

The still-water bending moment in Table 4 was described by a bimodal distribution (Ivanov et al. 2011). Considering that FPSOs are sometimes operated under still-water loads above the rule moment (Huang \& Moan 2005), 1.3 times the design still-water bending moment (IACS 2017) was employed. Moments minima were taken as $6 \%$ of the design moments. Furthermore, 0.6 coefficient of variation for both hogging and sagging was used.

Table 4. Random variables for the reliability analysis.

\begin{tabular}{|r|r|c|}
\hline Description & Unit & Distribution \\
\hline Still-water bending & $\mathrm{Nm}$ & $\begin{array}{c}\text { Bimodal from truncated normal for sagging }(\mu \\
\text { moment }\end{array}$ \\
& $=-1.347 \times 109, \sigma=8.08 \times 108, b_{l}=-2.57 \times 109, b_{u}$ \\
\hline
\end{tabular}




\begin{tabular}{|c|c|c|}
\hline & & $\begin{array}{r}\left.=-1.19 \times 108, K_{s}=0.6\right) \text { and truncated normal for } \\
\text { hogging }\left(\mu=1.735 \times 109, \sigma=1.04 \times 109, b_{l}\right. \\
\left.=1.53 \times 108, b_{u}=3.31 \times 109, K_{h}=0.4\right)\end{array}$ \\
\hline $\begin{array}{l}\text { Ultimate hull girder } \\
\text { strength in hogging }\end{array}$ & $\mathrm{Nm}$ & Log-normal $(\mu=22.99, \sigma=0.09975)$ \\
\hline $\begin{array}{l}\text { Ultimate hull girder } \\
\text { strength in sagging }\end{array}$ & $\mathrm{Nm}$ & Log-normal $(\mu=22.797, \sigma=0.09975)$ \\
\hline Ultimate strength for chain & $\mathrm{N}$ & Log-normal $(\mu=16.2826, \sigma=0.0499)$ \\
\hline $\begin{array}{r}\text { Ultimate strength for } \\
\text { polyester rope }\end{array}$ & $\mathrm{N}$ & Log-normal $(\mu=16.1148, \sigma=0.0499)$ \\
\hline
\end{tabular}

In Table 4, the mean of the hull resistance was taken as the ultimate strength for a double-hull oil tanker of similar dimensions with half corrosion addition (Kim et al. 2014) and the coefficient of variation was taken as 0.1 (Sun \& Bai 2001). The parameters for mooring lines resistances were taken from Vazquez-Hernandez et al. (2006).

A total of $1 \times 10^{6}$ Monte Carlo simulations were carried out for 47 variables. Fig. 4 illustrates the probability density functions (PDFs) for solicitations and resistances. Afterwards, limit state violations were evaluated, and the failure probabilities were then 
estimated in Fig. 5 as functions of a single disconnection criterion, where $H_{L}$ and $U_{L}$ have been normalized with respect to the $100 \mathrm{yr}$ return period significant wave height $H_{100}(10.13 \mathrm{~m})$ and $100 \mathrm{yr}$ return period 1 hour average wind speed $U_{100}\left(48 \mathrm{~m} \cdot \mathrm{s}^{-1}\right)$, respectively. It is concluded that $P_{f 2}<1 \times 10^{-6}$ and $P_{f 3}<1 \times 10^{-6}$.
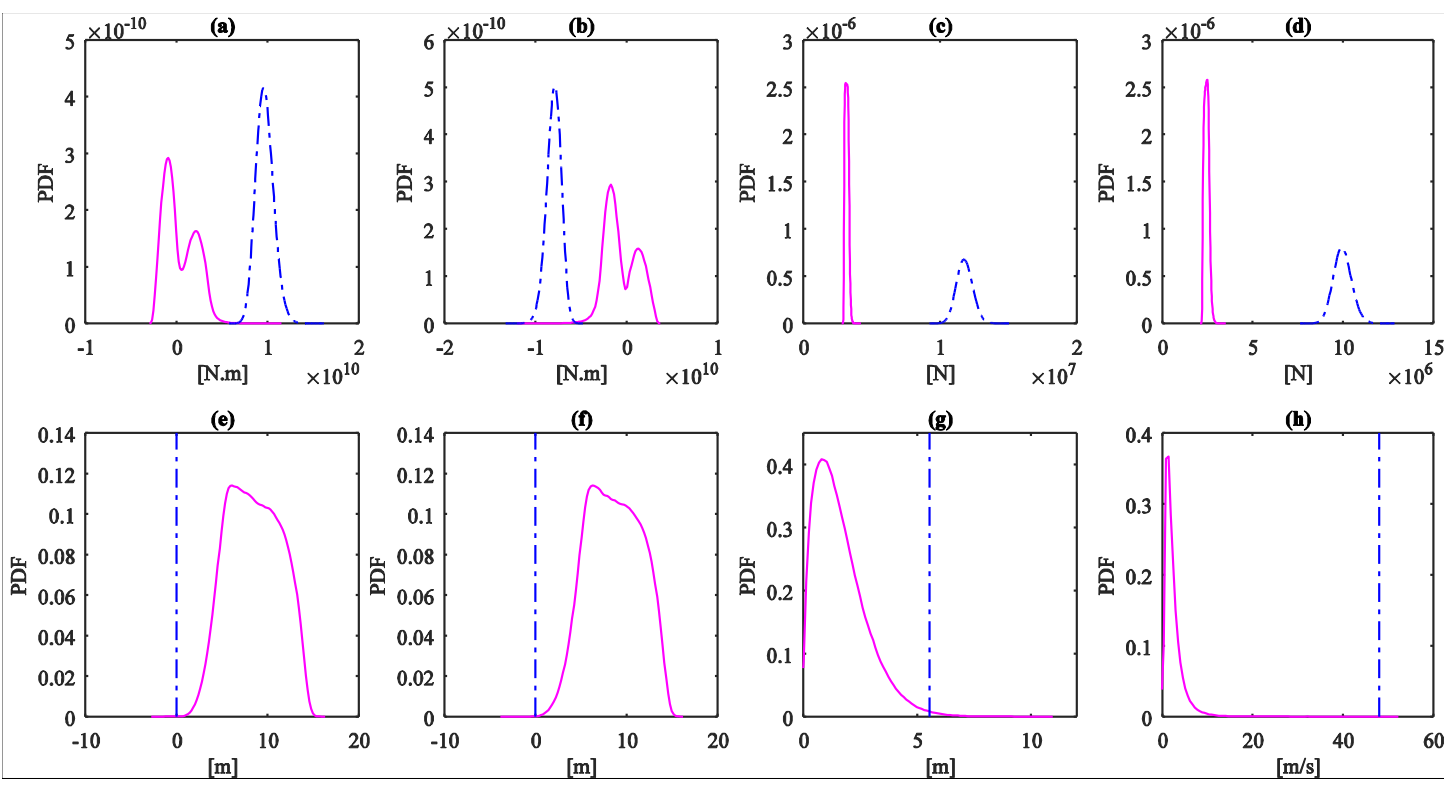

Figure 4. PDF of resistances (dot-dashed line) and solicitations (continuous line) for FPSO limit states without disconnection: (a) hogging bending moment, (b) sagging bending moment, (c) tension at top-chain section, (d) tension at intermediate polyester section, (e) green water at accommodation, (f) green water at bow, (g) significant wave height and optimum disconnection limit, (h) wind speed and optimum disconnection limit. 

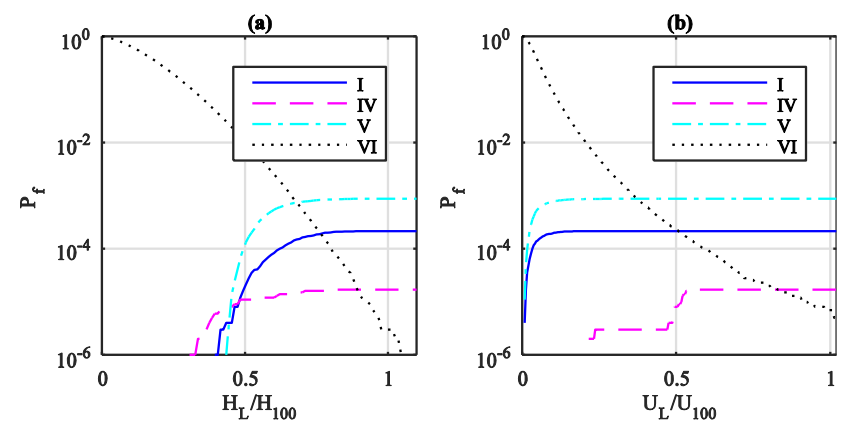

Figure 5. Probabilities of failure as function of (a) significant wave height limit and (b) wind speed limit.

\subsection{Life-cycle cost analysis}

Initial and future costs for replacement were calculated by means of QUE\$TOR, a capital/operational expenditure cost estimation software for oil and gas projects (IHS Markit 2017). Wounds, life loss and environmental damage costs were estimated based on local regulations. Reputational damage costs were taken as percentage of market value losses (Aon Oxford Metrica 2011) respect to environmental damage costs (BP 2015) for the Deepwater Horizon oil spill. Costs are summarized in Table 5 for $12 \%$ net annual discount rate.

Table 5. Equivalent cost of failure at $t=0$.

\begin{tabular}{|c|c|c|c|c|c|c|c|}
\hline Limit state & $\overline{C_{R}} / C_{I}$ & $\overline{C_{M}} / C_{I}$ & $\overline{C_{W}} / C_{I}$ & $\overline{C_{L}} / C_{I}$ & $\overline{C_{E D}} / C_{I}$ & $E\left[C_{D p}\right] /\left(C_{l} P_{f} \mathrm{PVF}\right)$ & $\overline{C_{R D}} / C_{I}$ \\
\hline (I) & 0.8937 & 0.0006 & 0.0000 & 0.0060 & $>30$ & 0.1892 & $>60$ \\
\hline (II) & 0.0021 & 0.0011 & 0.0000 & 0.0000 & 0.0000 & 0.0007 & 0.0000 \\
\hline
\end{tabular}




\begin{tabular}{|r|r|l|l|l|l|r|l|}
\hline (III) & 0.1063 & 0.0006 & 0.0023 & 0.0023 & 0.0091 & 0.1285 & 0.0163 \\
\hline (IV) & 0.0025 & 0.0004 & 0.0012 & 0.0012 & 0.0047 & 0.0011 & 0.0083 \\
\hline (V) & 0.0079 & 0.0004 & 0.0009 & 0.0009 & 0.0034 & 0.0011 & 0.0061 \\
\hline (VI) & 0.0000 & 0.0127 & 0.0000 & 0.0000 & 0.0000 & 0.0011 & 0.0000 \\
\hline
\end{tabular}

The revenue stream was obtained by calculating oil sales from the approximate production profile in Fig. 6 and then deducting production costs calculated with QUE\$TOR, royalties and taxes. In Fig. 6, the annual production rate $q_{t}$ is normalized with respect to the depletion rate at peak production $d_{a p}$.

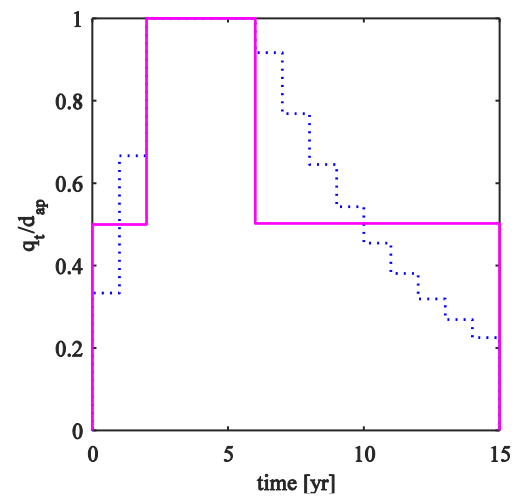

Figure 6. Actual (dotted line) and approximate (solid line) hydrocarbon liquid production profile. 


\section{Results}

\subsection{Calculated optimum disconnection criteria}

Life-cycle costs were evaluated for $0 \leq H_{L} / H_{100} \leq 1$ and $0 \leq U_{L} / U_{100} \leq 1$ in $50 \times 50$ mesh points. Results are plotted in Fig. 7(a). The optimum disconnection criteria were found at the cost minimum and associated variables are summarized in the second row of Table 6, where $C_{I_{0}}$ is the initial cost for the rule-based designed mooring system.

Fig. 8 shows that the solicitations are reduced after disconnection is implemented.
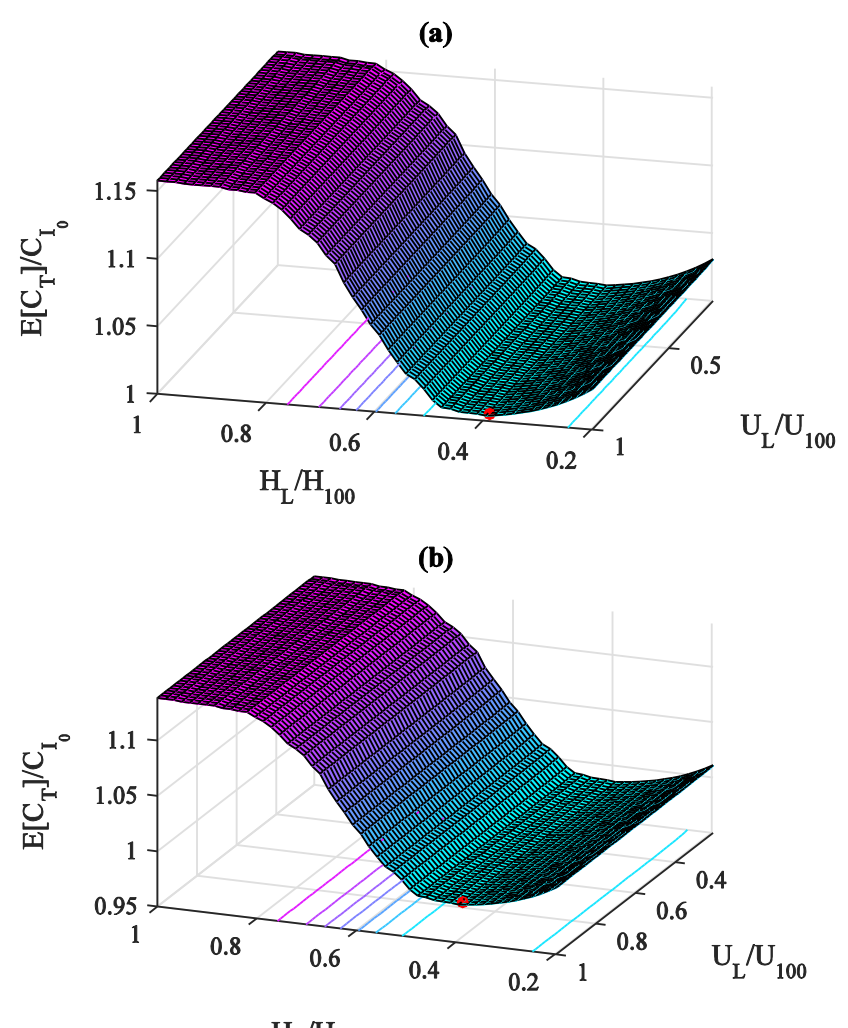

$\mathrm{H}_{\mathrm{L}} / \mathrm{H}_{100}$

Figure 7. Expected life-cycle cost for FPSO with (a) a rule-based designed mooring system and (b) an optimized mooring system (optimum is shown as red point). 
Table 6. Calculated optimum disconnection criteria and mooring lines reliability index.

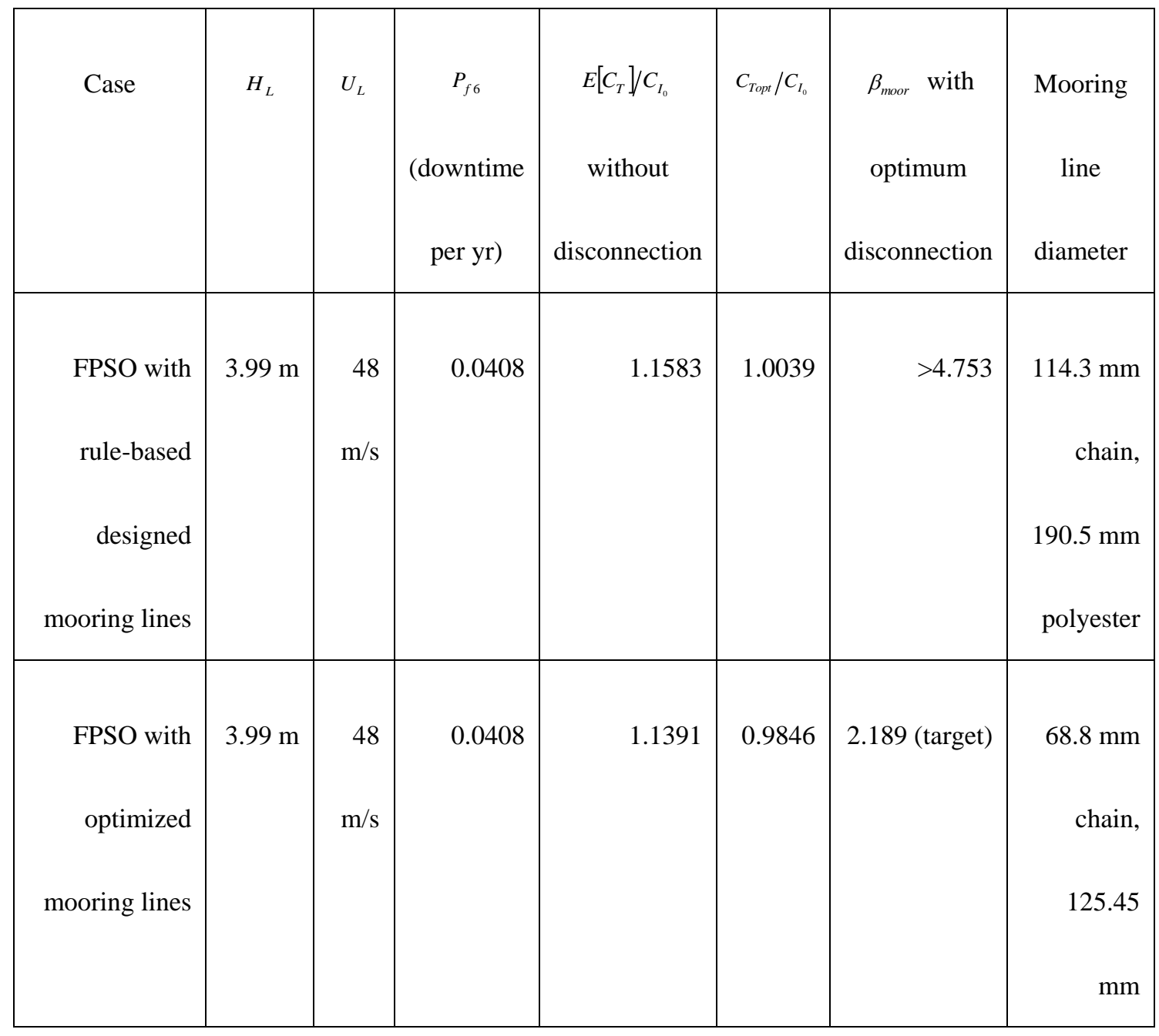



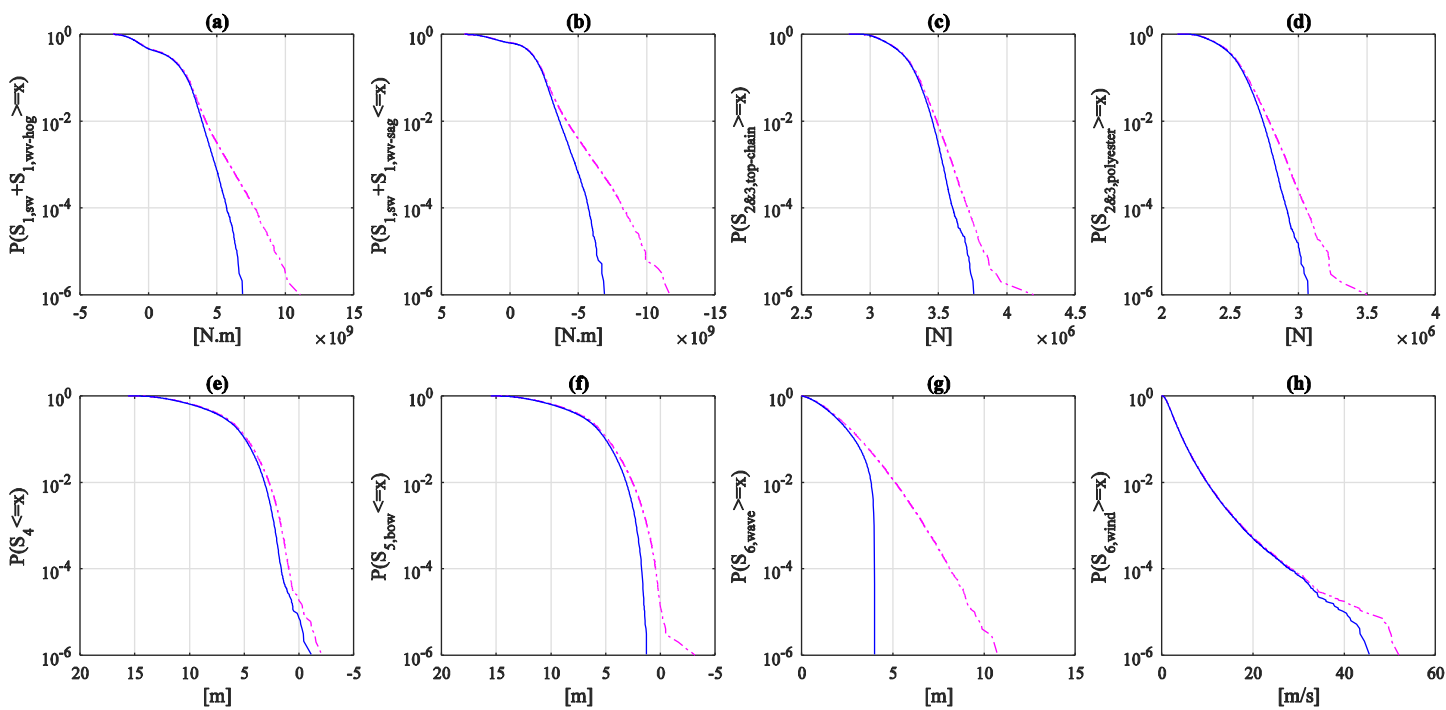

Figure 8. Exceedance curves for solicitations without disconnection (dash-dotted line) and with optimum disconnection (solid line).

\subsection{Calculated target reliability index for mooring system}

The optimum expected life-cycle costs were calculated as a function of the same MBL for all line sections, still holding different probabilistic distributions. First, relevant costs were calculated in Fig. 9. Monte Carlo simulation was then performed to obtain the resistance distribution for each mooring section. Afterwards, the optimum life-cycle costs were calculated as function of MBL (see Fig. 10). This approach assumes that the lines' loads remain unchanged. 


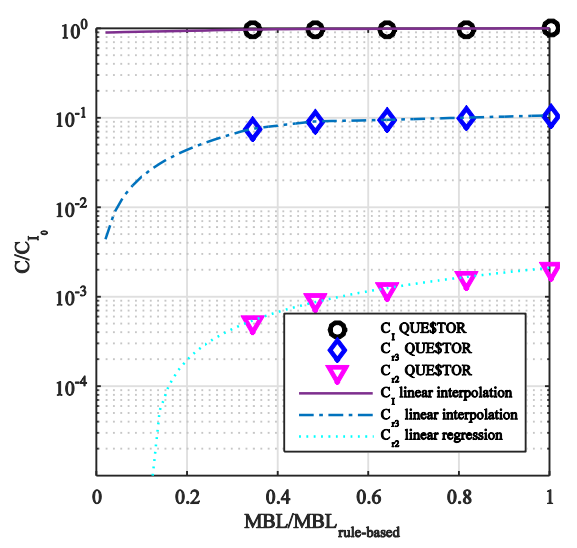

Figure 9. Initial and future costs at present time in association with mooring line resistance.

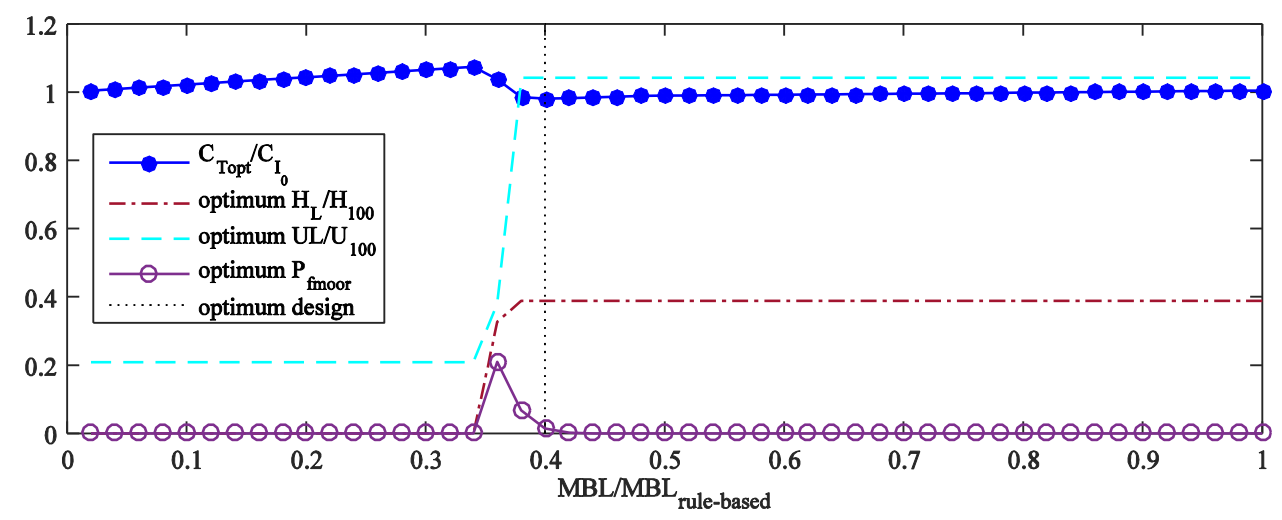

Figure 10. Optimum life-cycle cost and associated variables as function of mooring line resistance.

The costs for the optimized mooring system design are plotted in Fig. 7(b). The probability of failure at the optimum is $P_{\text {fmoor }}=1.43 \times 10^{-2}$ and the associated parameters are presented in the last row of Table 6 . The calculated target reliability index, 2.1897 , is recommended to be raised to 2.3 in order to comply with suggested values for the ULS design of structures with relative high effort to achieve reliability 
and insignificant expected failure consequences (Rackwitz 2000).

Fig. 11 illustrates how the safety margin has been optimized for the mooring lines. Fig.

12 shows that the probability of failure for the mooring system is dominated by the failure of one line rather than by the failure of two or more lines.

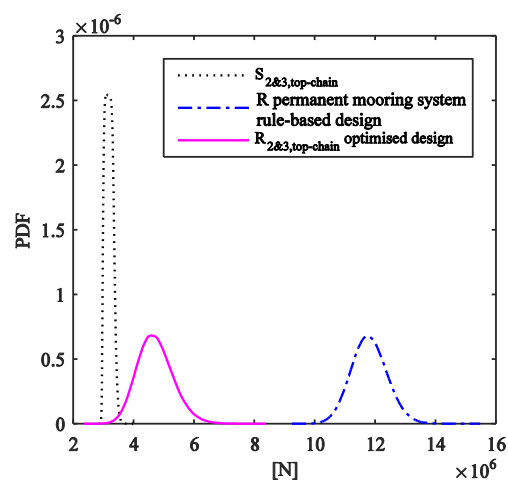

Figure 11. Comparison of PDF for solicitation and resistance before and after optimization.
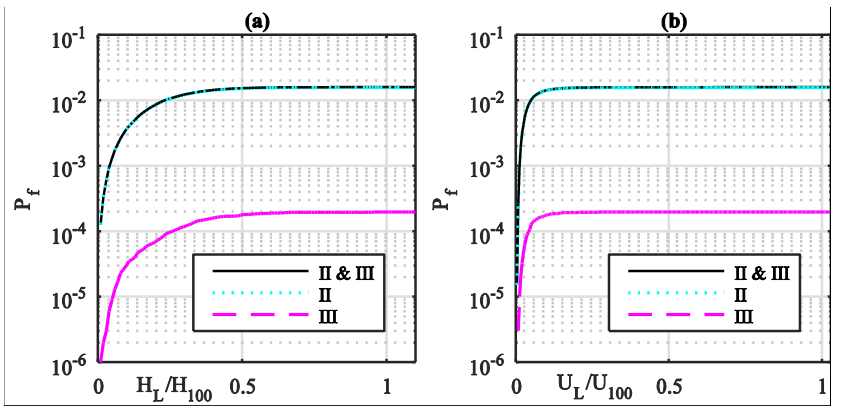

Figure 12. Probabilities of failure for optimum mooring system.

\section{Conclusions}

The objective of the present study has been to derive a target reliability index for the design of mooring lines of disconnectable FPSOs. Said goal has been fulfilled by means of a life-cycle cost model which can be used to optimize the disconnection 
criteria and subsequently to obtain a design criterion under reliability format.

A hypothetical tanker-shaped FPSO was used to illustrate the application of the model. The calculated target reliability index for the disconnectable mooring system is 2.189 and the limit significant wave height is $3.99 \mathrm{~m}$. Wind speed was found not to be a relevant parameter for this problem.

The results of the applied example show that savings of up to $17 \%$ of the initial cost of the project can be achieved if optimization of the disconnectable mooring system is carried out (see Table 6). Although these features cannot be generalized, cuts to capital and risk expenditures for FPSO projects can be expected if the proposed optimizations are implemented.

\section{Acknowledgements}

This study was undertaken at the Korea Ship and Offshore Research Institute at Pusan National University which has been a Lloyd's Register Foundation (LRF) Research Centre of Excellence since 2008. This work was supported by a 2-Year Research Grant of Pusan National University. The authors are grateful to Dr. Alberto Omar Vazquez-Hernandez of the Mexican Petroleum Institute (IMP) for his valuable discussion on the design of mooring systems. The first author would like to acknowledge the scholarship from the Mexican National Council for Science and Technology (CONACYT). The second author wishes to thank the financial support of PRH-15 ANP program.

\section{Disclosure statement}

No potential conflict of interest was reported by the authors. 


\section{References}

Aanesland V, Kaalstad JP, Bech A, Holm A, Production NF. 2007. Disconnectable FPSO_Technology To Reduce Risk in GoM. In: Offshore Technol Conf. Houston, USA; p. OTC 18487.

[ABS] American Bureau of Shipping. 2014. Rules for building and classing Floating Production Instalations. Houston, USA.

[API] American Petroleum Institute. 2001. Recommended Practice for Planning, Designing, and Constructing Floating Production Systems, API Recommended Practice 2FPS. First. Washington, D.C.

[API] American Petroleum Institute. 2005. Design and Analysis of Stationkeeping Systems for Floating Structures Recommended Practice 2SK. Third. Washington, D.C. [API] American Petroleum Institute. 2007. Interim Guidance on Hurrican Conditions in the Gulf of Mexico API Bulletin 2INT-MET. Washington, D.C.

Aon Oxford Metrica. 2011. Reputation Review, Improving Financial Performance with Measured Communications [Internet]. [cited 2017 Sep 19]. Available from: http://www.oxfordmetrica.com/public/CMS/Files/825/Aon_Oxford Metrica Reputation Review_2011.pdf

Bea RG. 1994. Evaluation of Alternative Marine Structural Integrity Programs. Mar Struct. 7:77-90.

Béghin D. 2010. Reliability-Based Structural Design. In: Hughes OF, Paik JK, editors. Sh Struct Anal Des. Jersey City, New Jersey: The Society of Naval Architects and Marine Engineers; p. 5-1-5-63.

[BP] BP Exploration \& Production. 2015. Gulf of Mexico Environmental Recovery and Restoration [Internet]. [cited 2017 Sep 19]. Available from: http://www.bp.com/content/dam/bp-country/en_us/PDF/GOM/BP_Gulf_Five_Year_ Report.pdf. 
Cabrera-Miranda JM, Paik JK. 2017. On the probabilistic distribution of loads on a marine riser. Ocean Eng. 134:105-118.

Campos D, Cabrera Miranda JM, Martínez Mayorga JM, García Tenorio M. 2013.

Optimal Metocean Design of Offshore Tower Structures. In: Proc ASME 2013 32nd Int Conf Ocean Offshore Arct Eng OMAE2013. Nantes, France: ASME; p.

OMAE2013-10953.

Campos D, Ortega C, Alamilla JL, Soriano A. 2015. Selection of Design Lower Deck Elevation of Fixed Offshore Platforms for Mexican Code. J Offshore Mech Arct Eng. $137: 51301-1-51301-8$.

Couckuyt I, Declercq F, Dhaene T, Rogier H, Knockaert L. 2010. Surrogate-based infill optimization applied to electromagnetic problems. Int J RF Microw Comput Eng. 20:492-501.

Couckuyt I, Forrester A, Gorissen D, De Turck F, Dhaene T. 2012. Blind Kriging: Implementation and performance analysis. Adv Eng Softw. 49:1-13.

Dalgic Y, Lazakis I, Dinwoodie I, McMillan D, Revie M, Majumder J. 2015. Cost benefit analysis of mothership concept and investigation of optimum chartering strategy for offshore wind farms. Energy Procedia. 80:63-71.

Dalgic Y, Lazakis I, Turan O, Judah S. 2015. Investigation of optimum jack-up vessel chartering strategy for offshore wind farm O \& M activities. Ocean Eng. 95:106-115.

Daniel J, Mastrangelo CF, Ganguly P. 2013. First Floating, Production Storage and Offloading vessel in the U.S. Gulf of Mexico. In: Offshore Technol Conf. Houston, USA; p. OTC 24112.

[DNV] Det Norske Veritas AS. 2014. Recommended practice DNV-RP-C205, Environmental Conditions and Environmental Loads. Oslo, Norway.

DNV GL. 2015. Offshore Standard DNVGL-OS-E301, Position mooring. Oslo, Norway. 
Eckert C, Gatzert N. 2017. Modeling operational risk incorporating reputation risk: An integrated analysis for financial firms. Insur Math Econ. 72:122-137.

Faber MH, Straub D, Heredia-Zavoni E, Montes-Iturrizaga R. 2012. Risk assessment for structural design criteria of FPSO systems. Part I: Generic models and acceptance criteria. Mar Struct. 28:120-133.

Fang K, Li RZ, Sudjianto A. 2006. Design and modeling for computer experiments. Boca Raton, FL, USA: Chapman \& Hall/CRC.

Garrè L, Rizzuto E. 2012. Bayesian networks for probabilistic modelling of still water bending moment for side-damaged tankers. Ships Offshore Struct. 7:269-283.

Heredia-Zavoni E, Montes-Iturrizaga R, Faber MH, Straub D. 2012. Risk assessment for structural design criteria of FPSO systems. Part II: Consequence models and applications to determination of target reliabilities. Mar Struct. 28:50-66.

Huang W, Moan T. 2005. Combination of global still-water and wave load effects for reliability-based design of floating production, storage and offloading (FPSO) vessels. Appl Ocean Res. 27:127-141.

IHS Markit. 2017. QUE\$TOR

(https://www.ihs.com/products/questor-oil-gas-project-cost-estimation-software.html)

[IACS] International Association of Classification Societies. 2017. Common Structural Rules for Bulk Carriers and Oil Tankers. London, UK.

Ivanov LD, Ku A, Huang B-Q, Krzonkala VCS. 2011. Probabilistic presentation of the total bending moments of FPSOs. Ships Offshore Struct. 6:45-58.

Kim DK, Kim HB, Zhang X, Li CG, Paik JK. 2014. Ultimate strength performance of tankers associated with industry corrosion addition practices. Int J Nav Archit Ocean Eng. 6:507-528.

Kübler O, Faber MH. 2004. Optimality and Acceptance Criteria in Offshore Design. J 
Offshore Mech Arct Eng. 126:258-264.

Lagaros ND, Karlaftis MG, Paida MK. 2015. Stochastic life-cycle cost analysis of wind parks. Reliab Eng Syst Saf. 144:117-127.

Langfitt Q, Haselbach L. 2016. Coupled oil analysis trending and life-cycle cost analysis for vessel oil-change interval decisions interval decisions. J Mar Eng Technol. $15: 1-8$

Lee S, Jo C, Bergan P, Pettersen B, Chang D. 2016. Life-cycle cost-based design procedure to determine the optimal environmental design load and target reliability in offshore installations. Struct Saf. 59:96-107.

Leon A. 2016. Breaking new frontiers. Offshore Eng Sept.:22-25.

De Leon D, Ang AHS. 2008. Confidence bounds on structural reliability estimations for offshore platforms. J Mar Sci Technol. 13:308-315.

Li D, Yi C, Xu Z, Bai X. 2014. Scenario Research and Design of FPSO in South China. In: Proc Twenty-fourth Int Ocean Polar Eng Conf. Busan, Korea: International Society of Offshore and Polar Engineers (ISOPE); p. 964-969.

[LR] Lloyd's Register. 2016. Rules and Regulations for the Classification of Offshore Units. London: Lloyd's Register Group Limited.

Mastrangelo C, Barwick K, Fernandes L, Theisinger E. 2007. FPSOs in the Gulf of Mexico [presentation material]. In: Inf Transf Meet. Kenner, Louisiana, USA.

Moan T. 2011. Life-cycle assessment of marine civil engineering structures. Struct Infrastruct Eng. 7:11-32.

Noble Denton Europe Ltd. 2001. Rationalisation of FPSO design issues-Relative reliability levels achieved between different FPSO limit states. Norwich: Health \& Safety Executive.

Nwaoha TC. 2014. Inclusion of hybrid algorithm in optimal operations of liquefied natural gas transfer arm under uncertainty. Ships Offshore Struct. 9:514-524. 
Rackwitz R. 2000. Optimization - the basis of code-making and reliability verification. Struct Saf. 22:27-60.

Shimamura Y. 2002. FPSO/FSO : State of the art. J Mar Sci Technol. 7:59-70.

Stahl B. 1986. Reliability Engineering and Risk Analysis. In: McClelland B, Reifel MD, editors. Plan Des fixed offshore platforms. New York: Van Nostrand Reinhold Company; p. 59-98.

Stahl B, Aune S, Gebara JM, Cornell CA. 2000. Acceptance Criteria for Offshore Platforms. J Offshore Mech Arct Eng. 122:153.

Sun H-H, Bai Y. 2001. Time-Variant Reliability of FPSO Hulls. SNAME Trans. 109:341-366.

Temple D, Collette M. 2017. Understanding lifecycle cost trade-offs for naval vessels: minimising production, maintenance, and resistance. Ships Offshore Struct. 12:756766.

Ulaganathan S, Couckuyt I, Deschrijver D, Laermans E, Dhaene T. 2015. A Matlab toolbox for Kriging metamodelling. Procedia Comput Sci. 51:2708-2713. Vazquez-Hernandez AO, Ellwanger GB, Sagrilo LVS. 2006. Reliability-based comparative study for mooring lines design criteria. Appl Ocean Res. 28:398-406. Yang HZ, Zheng W. 2011. Metamodel approach for reliability-based design optimization of a steel catenary riser. J Mar Sci Technol. 16:202-213. 